\title{
Caveolin-1 mediates chemoresistance in cisplatin-resistant ovarian cancer cells by targeting apoptosis through the Notch-1/Akt/NF-kB pathway
}

\author{
WEI ZOU*, XIANGDONG MA*, WEI HUA, BILIANG CHEN and GUOQING CAI \\ Department of Obstetrics and Gynecology, Xijing Hospital, The Fourth Military Medical University, \\ Xi'an, Shaanxi 710032, P.R. China
}

Received May 19, 2015; Accepted June 26, 2015

DOI: $10.3892 /$ or.2015.4320

\begin{abstract}
Caveolin-1 (Cav-1), a family of ubiquitously expressed oligomeric structural proteins in many mammalian cells, has been shown to be an effective regulator of tumorigenesis. Recent studies have indicated that Cav-1 can promote resistance to chemotherapy in a variety of tumors. However, the regulation of Cav-1 on chemoresistance in ovarian cancer is still unknown. In the present study, the mRNA and protein expression level was investigated by RT-PCR and western blot analysis, respectively, and the $50 \%$ inhibitory concentration $\left(\mathrm{IC}_{50}\right)$ value was measured by MTT assay. The protein expression level of P-glycoprotein (P-gp), Notch-1, p-Akt and $\mathrm{p}-\mathrm{NF}-\mathrm{\kappa B}$ p65 were detected using western blot analysis and the apoptotic ratio was determined using the Annexin V-FITC/PI detection kit. The results showed that the mRNA and protein expression levels of Cav-1 were significantly higher in SKOV3/DDP and A2780/DDP than in SKOV3 and A2780, respectively. Knockdown of Cav-1 significantly decreased the $\mathrm{IC}_{50}$ value in cisplatin-resistant cells. The protein expression level of P-gp in SKOV3/DDP and A2780/DDP was significant higher than SKOV3 and A2780, respectively, and had no correlation with the Cav-1 siRNA transfection. The apoptotic ratio induced by cisplatin in normal ovarian cancer cells was higher than cisplatin-resistant ovarian cancer cells, and knockdown of Cav-1 could significantly enhance cisplatin induced cell apoptosis. Furthermore, knockdown of Cav-1 was also able to significantly downregulate the protein expression level of
\end{abstract}

Correspondence to: Dr Guoqing Cai, Department of Obstetrics and Gynecology, Xijing Hospital, The Fourth Military Medical University, 127 Changle West Road, Xi'an, Shaanxi 710032, P.R. China

E-mail: guoqingcaixj@163.com

${ }^{*}$ Contributed equally

Abbreviations: Cav-1, caveolin-1; P-gp, P-glycoprotein; $\mathrm{IC}_{50}, 50 \%$ inhibitory concentration; MDR, multi-drug resistance

Key words: caveolin-1, ovarian cancer, chemoresistance, apoptosis
Notch-1, p-Akt and p-NF- $\mathrm{kB}$ p65 in cisplatin-resistant ovarian cancer cells. Overexpression of Cav-1 upregulated the $\mathrm{IC}_{50}$ value, but under the effect of Notch-1 siRNA or LY294002 or PDTC, the $\mathrm{IC}_{50}$ value was markedly decreased. Our results suggested that Cav-1 can promote the chemoresistance of ovarian cancer by targeting apoptosis through the Notch-1/ Akt/NF-kB pathway.

\section{Introduction}

Ovarian cancer is a common malignant tumor in females and the leading cause of mortality among gynecologic cancers (1). The main therapeutic strategy of ovarian cancer is a combination of surgery and chemotherapy, which however contributes to chemoresistance. Chemoresistance is considered one of the main obstacles in the clinical treatment of ovarian cancer patients (2), thus, it is meaningful to figure out the relevant molecules and mechanisms that are involved in the development of chemoresistance.

Caveolines, a family of ubiquitously expressed oligomeric structural proteins in many mammalian cells, are important proteins of caveolae, which are related to endocytosis, transcytosis and the integration of various signaling molecules and signaling pathways (3). Three caveolin family members, caveolin (Cav)-1, -2 and -3 , have been identified and are widely expressed in various tissues in which Cav-1 is essential for caveolae formation and aggregation of signal molecules. Cav-1 has phosphorylated sites at tyrosine residue 14 and serine 80 and the phosphorylation is related to epidermal growth factor, platelet-derived growth factor, insulin and Akt pathways (4). Various signaling molecules, such as $\mathrm{G}$ protein-coupled receptors, protein kinase $\mathrm{C}$ and extracellular signal regulated protein kinase interact with Cav-1 through its caveolin-scaffolding domain $(5,6)$. Studies have demonstrated the role of Cav-1 in progression and metastasis of lung cancer (7), renal cell carcinoma (8), rectal (9), pancreatic (10), breast $(11,12)$ and ovarian cancer $(13)$ by regulating cell cycle, proliferation, survival and migration of tumor cells (14). Cav-1 was regarded as a tumor suppressor for years until overexpression of Cav-1 was found in chemoresistant breast, colon and lung cancer (15-17), thus, Cav-1 is both a tumor suppressor and a promoter of multi-drug resistance (MDR). 
Wiechen et al (18) proposed that Cav-1 also acts as a candidate tumor suppressor gene in human ovarian carcinoma, but the relationship between Cav-1 and chemoresistance in ovarian cancer is still unknown.

Notch-1 is one of the mammalian Notch gene family members, which plays a crucial role in cell proliferation and apoptosis. It is reported that Notch-1 may promote cell growth and inhibit apoptosis via activation of the Akt signaling pathway (19). PI3K/Akt is an important anti-apoptotic and survival pathway which plays a crucial role in cisplatin resistance (20). NF- $\kappa$ B DNA-binding activity, another major regulator of cell proliferation, is also decreased by downregulation of Notch-1 (21). NF- $\kappa \mathrm{B}$ is also an effector of the Akt pathway (22). Recent studies suggested a significant association between the expression of Notch, pAkt and NF- $\mathrm{BB}$ in breast cancers and the Akt1/NF- $\kappa \mathrm{B} /$ Notch1/PTEN axis is involved in chemoresistance of gastric cancer cells $(23,24)$. Cav-1 has been found to cross-talk with the Notch-1, Akt and $\mathrm{NF}-\kappa \mathrm{B}$ pathway in various cancer cells (25-27).

The present study investigated the role of Cav-1 in regulating the chemoresistance of ovarian cancer cells and we hypothesized that Cav-1 is overexpressed in chemoresistant ovarian cancer cells. We transfected Cav-1 siRNA to knockdown Cav-1 and confirm the connection between Cav-1 and chemoresistance of ovarian cancer. The role of MDR protein P-gp and apoptosis in the Cav-1 mediated cisplatin resistance was assessed. Subsequently, the involvement of the Notch-1/Akt/NF- $\kappa \mathrm{B}$ signaling pathway was investigated. As the first study addressing the role of Cav-1 in the chemoresistance of ovarian cancer, our purpose was to provide a new direction to improve the chemosensitivity of ovarian cancer and thus, provide possibilities for the cure of ovarian cancer.

\section{Materials and methods}

Cell culture. Human ovarian cancer cell lines SKOV3 and A2780 and human cisplatin-resistance ovarian cancer cell lines SKOV3/DDP and A2780/DDP were obtained from the American Type Culture Collection (ATCC, Manassas, VA, USA). Cells were cultured in RPMI-1640 (Gibco BRL, Gaithersburg, MD, USA) supplemented with 5\% fetal bovine serum (Gibco) and 1\% penicillin and streptomycin (Gibco, Life Technologies, Lofer, Austria) at $37^{\circ} \mathrm{C}$ in a humidified incubator with $5 \% \mathrm{CO}_{2}$.

Analysis of the $50 \%$ inhibitory concentration $\left(I C_{50}\right)$. For the determination of $\mathrm{IC}_{50}$, cells were seeded in 96-well plates and $24 \mathrm{~h}$ later, the media were replaced with 4, 8, 12, 16, 20, 24, 28, 32,36 and $40 \mu \mathrm{g} / \mathrm{ml}$ cisplatin medium and cultured for $48 \mathrm{~h}$. MTT was then added and incubated for $4 \mathrm{~h}$. The supernatant was removed and DMSO was added. The absorbance at $490 \mathrm{~nm}$ was read using a microplate reader (Bio-Rad Laboratories, Hercules, CA, USA). Three independent experiments were performed for each experiment.

Real-time PCR analysis. Total RNA was extracted from cells using TRIzol reagent (Invitrogen, Carlsbad, CA, USA) according to the manufacturer's instructions. After the purity and concentration were determined, total RNA was reverse transcribed using High-Capacity RNA-to-cDNA kit (Applied
Biosystems, Foster City, CA, USA) according to the manufacturer's instructions. RT-PCR was performed using a SYBR-Green supermix (Invitrogen) on the ABI PRISM 7700 Sequence Detection system (Perkin-Elmer Biosystems, Waltham, MA, USA) and $\beta$-actin was used as a reference. The primers for $\mathrm{Cav}-1$ and $\beta$-actin were designed as follows: Cav-1 forward, 5'-AACACGTAGCTAGCTGCCCTTCAG-3' and reverse, 5'-GGATGGGAACGGTGTTAGAGAT-3' and $\beta$-actin forward, 5'-AGGCCAACCGTGAAAAGATG-3' and reverse, 5'-TGGCGTGAGGGAGAGCATAG-3'. The expression levels of the relative genes were calculated using $\beta$-actin mRNA as a control using the $2^{-\Delta \Delta \mathrm{CT}}$ method (28).

Western blot analysis. Total protein was extracted from cells using TIPA lysis buffer (Beyotime, Jiangsu, China) and the concentration was measured using the BCA kit (Beyotime). The proteins were separated on $10 \%$ SDS-PAGE and then transferred onto polyvinylidene difluoride membrane. After blocking for $4 \mathrm{~h}$ in $5 \%$ skim milk, the membrane was immunoblotted with primary antibodies for rabbit anti-caveolin-1, rabbit anti-p-Akt, rabbit anti p-NF- $\mathrm{B}$ p65, goat anti P-gp and $\beta$-actin (Santa Cruz Biotechnology, Dallas, TX, USA) overnight at $4^{\circ} \mathrm{C}$. Membranes were washed three times and incubated with the HRP-conjugated goat anti-rabbit IgG or HRP-conjugated mouse anti-goat IgG (Santa Cruz Biotechnology) for $1 \mathrm{~h}$. Chemiluminescent detection was performed using the ECL kit (Pierce Chemical, Rockford, IL, USA).

Plasmids and siRNA transfection. For overexpression of Cav-1, the plasmid pcDNA 3.1(+)-cav-1 (Addgene, Cambridge, MA, USA) or its empty vector pcDNA 3.1 (Invitrogen) was transfected into SKOV3/DDP and A2780/DDP cells using Lipofectamine 2000 (Invitrogen) according to the manufacturer's instructions. After transfection for $24 \mathrm{~h}$, the culture medium was changed to a selection medium that contained $1.5 \mathrm{mg} / \mathrm{ml}$ of geneticin and cultured for $48 \mathrm{~h}$ to select the transfected cells.

For knockdown of Cav-1 and Notch-1, the cells were transfected with Cav-1, Notch-1 or the control siRNA using Lipofectamine 2000 (Invitrogen) according to the manufacturer's instructions and incubated for $24 \mathrm{~h}$. Then, the transfected cells were harvested for further analysis. The Cav-1 siRNA target sequence: 5'-UCUGUGAUCCACUCU UUGAUU-3', Notch-1-siRNA target sequence: 5'-AAGTGG GACCTGCCTGAATGG-3'.

Annexin V-FITC analyses. The apoptotic ratio was detected by Annexin V-FITC/PI assay. Forty-eight hours after transfecting with siRNA, cells were exposed to $20 \mu \mathrm{M}$ cisplatin for $48 \mathrm{~h}$ and then the cells were collected and washed 3 times with PBS. Cells were suspended in PBS to $1 \times 10^{5} / \mathrm{ml}$, then $5 \mu \mathrm{l}$ of FITC Annexin V and $5 \mu \mathrm{l}$ PI was added to stain the cells. Cells were incubated for $15 \mathrm{~min}$ in the dark and the apoptotic cells were analyzed by flow cytometry.

Statistical analysis. All data were presented as mean \pm the standard error of the mean (SEM). The difference between treatments was compared by the Student's t-test or one-way ANOVA. A value of $\mathrm{P}<0.05$ was considered statistically significant. All experiments were repeated at least three times. 
A

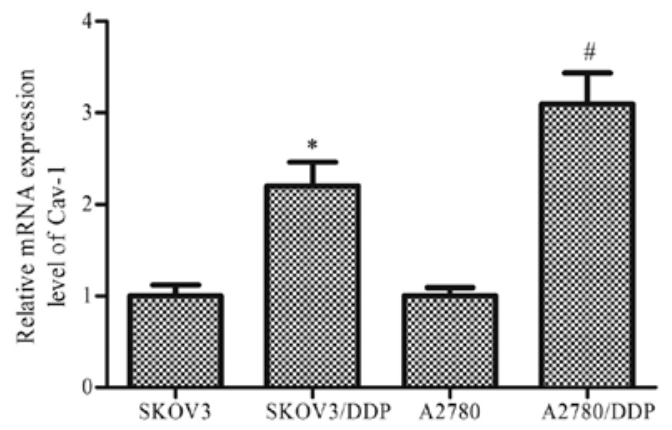

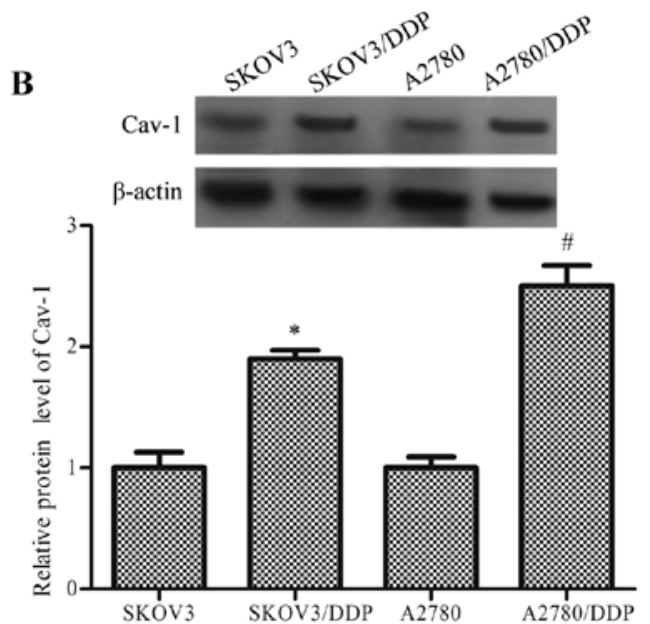

Figure 1. The mRNA and protein expression level of Cav-1 in the normal and cisplatin-resistant ovarian cancer cells. (A) Cav-1 mRNA level was measured by RT-PCR and normalized to the housekeeping gene $\beta$-actin. (B) The level of Cav-1 protein was quantified by western blot analysis. Data are normalized to $\beta$-actin values. All experiments were repeated at least three times with similar results. Data are shown as mean $\pm \mathrm{SEM}(\mathrm{n}=5)$. ${ }^{*} \mathrm{P}<0.05$ vs. $\mathrm{SKOV} 3,{ }^{\sharp} \mathrm{P}<0.05$ vs. A2780. Cav-1, caveolin-1.

\section{Results}

Cav-1 expression in cisplatin-resistant ovarian cancer cells. To evaluate the expression level of Cav-1 between normal ovarian cancer cells and cisplatin-resistant cancer cells, SKOV3 and A2780 (normal ovarian cancer cells) and SKOV3/DDP and A2780/DDP (cisplatin-resistant ovarian cancer cells) were cultured. The expression level of Cav-1 was measured using RT-PCR and western blot analysis. The results showed that both the mRNA and protein expression level of Cav-1 in SKOV3/DDP and A2780/DDP cells was significantly higher than SKOV3 and A2780 cells, respectively ( $\mathrm{P}<0.05$, Fig. 1). Thus, we predicted Cav-1 may be an important factor involved in the chemoresistance in ovarian cancer cells.

Cav-1 silencing promotes chemosensitivity in cisplatinresistant ovarian cancer cells. To explore the correlation between Cav-1 and the cisplatin resistance in ovarian cancer cells, we used Cav-1 siRNA to knock down Cav-1 and performed chemosensitivity analysis on cisplatin-resistant cells. The results showed that Cav-1 siRNA significantly inhibited the mRNA and protein expression level of Cav-1 (P<0.05, Fig. 2) and lowered the $\mathrm{IC}_{50}$ value of cisplatin from $28.21 \pm 1.35$ to $10.56 \pm 1.28(\mu \mathrm{M})$ in the SKOV3/DDP cells and from 35.39 \pm 3.18 to $9.17 \pm 1.32(\mu \mathrm{M})$ in the A2780/DDP cells (Fig. 2C) and the statistical analysis was significant for both SKOV3/DDP and A2780/DDP cells $(\mathrm{P}<0.05)$.

Cav-1 knockdown do not affect the protein expression level of $P$-glycoprotein $(P-g p)$. P-gp is a protein product of the MDR1 gene, which is one of the common genes that directly regulates drug resistance in various types of cancer. To figure out the relationship between Cav-1 and P-gp, we studied the P-gp expression level in cisplatin-resistant ovarian cancer cells with Cav-1 knockdown. The results showed that the relative protein expression level of P-gp was significantly higher in SKOV3/DDP than SKOV3 and higher in A280/DDP than A2780 ( $P<0.05$, Fig. 3). There was no significant difference in the protein expression level of P-gp in SKOV3/DDP and
A2780/DDP between the Cav-1 siRNA group and the blank or control siRNA group ( $\mathrm{P}>0.05$, Fig. 3$)$.

Cav-1 knockdown promotes apoptosis of cisplatin-resistant ovarian cancer cells. Apoptosis contributes to the antitumor activity of many chemotherapeutic drugs and plays a crucial role in drug-induced cytotoxicity, thus the decreased apoptosis ratio is also one of the common mechanisms that induce chemoresistance (29). For this reason, we assessed the apoptotic cells in Cav-1 knockdown cisplatin-resistant cells after exposure to $20 \mu \mathrm{M}$ cisplatin. The result showed that the ratio of apoptosis induced by cisplatin in SKOV3 and A2780 cells was significantly higher than SKOV3/DDP or SKOV3/DDP cells $(\mathrm{P}<0.05)$. Cav-1 siRNA transfection could significantly inhibited apoptosis of SKOV3/DDP and A2780/DDP compared to the blank and control siRNA groups $(\mathrm{P}<0.05$, Fig. 4).

Cav-1 knockdown inhibits Notch-1, Akt and NF- $\kappa B$ expression in ovarian cancer cells. Evidence has indicated that Notch-1 is an important regulator of chemoresistance of ovarian cancer cells (30). Phosphorylated Akt is an activated state of Akt, which is related to cancer cell survival and cisplatin resistance of ovarian cancer cells (31). Translocation of the NF- $\kappa \mathrm{B}$ p65 subunit has been reported to exert important roles in the cell survival of cancer cells (24) and the phosphorylation of p65 is essential for the nuclear retention and transcriptional activity of NF- $\mathrm{NB}$ (32). To probe the distinctive expression of Notch-1 in cisplatin-resistant ovarian cancer cells, we detected the protein level of Notch-1 using western blot analysis. The results showed that the protein level of Notch-1 was significantly upregulated in cisplatin-resistant ovarian cancer cells $(\mathrm{P}<0.05$, Fig. 5A and B). Likewise, the phosphorylation of Akt and NF- $\kappa \mathrm{B}$ p65 was also tested using western blot analysis and both were significantly upregulated in cisplatin-resistant ovarian cancer cells ( $\mathrm{P}<0.05$, Fig. 5A, $\mathrm{C}$ and $\mathrm{D})$.

To investigate whether the Notch-1/Akt/NF- $\kappa$ B pathway was related to the expression level of Cav-1, we inhibited the expression of Cav-1 by transfecting with Cav-1 siRNA and detected 

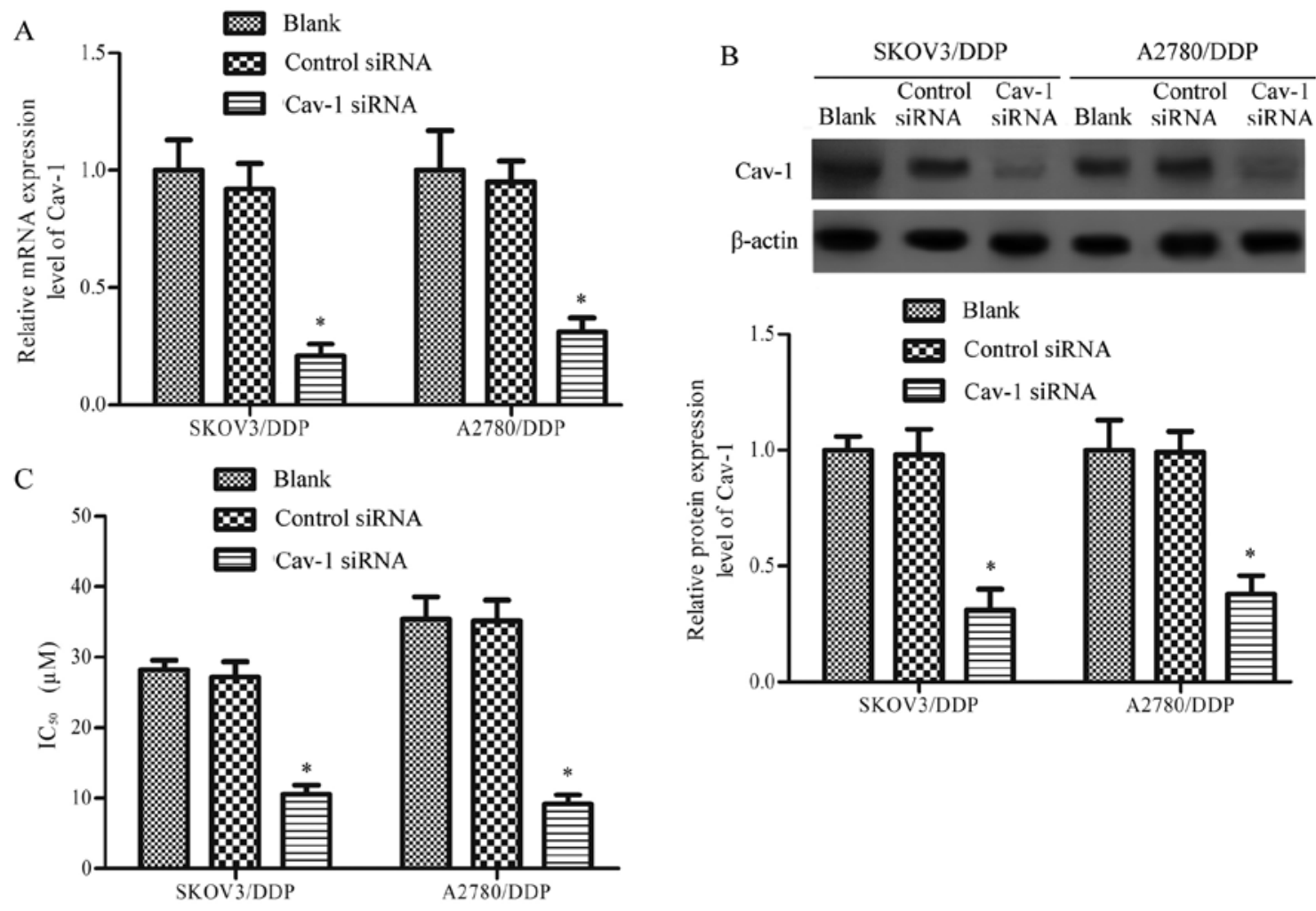

Figure 2. Cav-1 siRNA transfection inhibited the expression of Cav-1 and the $\mathrm{IC}_{50}$ of cisplatin in cisplatin-resistant ovarian cancer cells. (A) The level of Cav-1 mRNA in cisplatin-resistant ovarian cancer cells transfected with Cav-1 siRNA was detected by RT-PCR. (B) Western blot analysis of Cav-1 expression after Cav-1 siRNA transfection. Protein expression is presented as the relative Cav-1 to $\beta$-actin expression. (C) The $\mathrm{IC}_{50}$ value of cisplatin in SKOV3/DDP and A2780/DDP cells transfected with Cav-1 siRNA was evaluated by MTT assay. All experiments were repeated at least three times with similar results. Data are shown as mean \pm SEM $(n=5)$. ${ }^{*} \mathrm{P}<0.05$ vs. blank. Cav-1, caveolin-1.

A
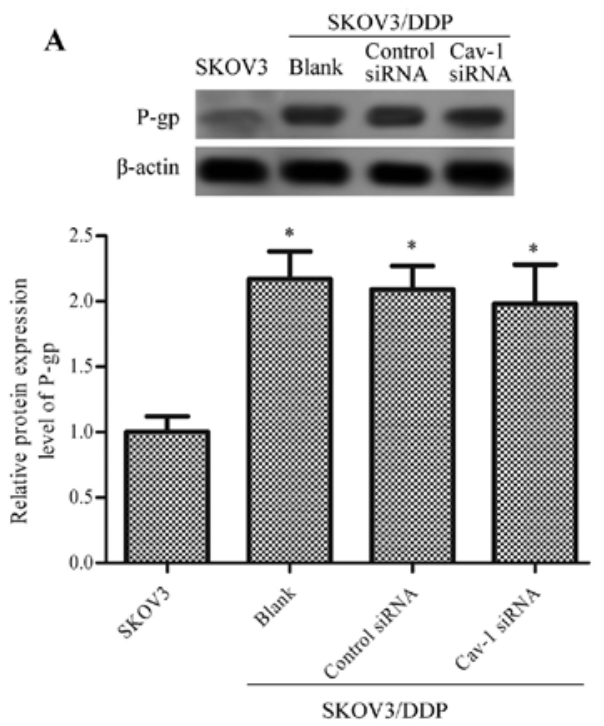

B
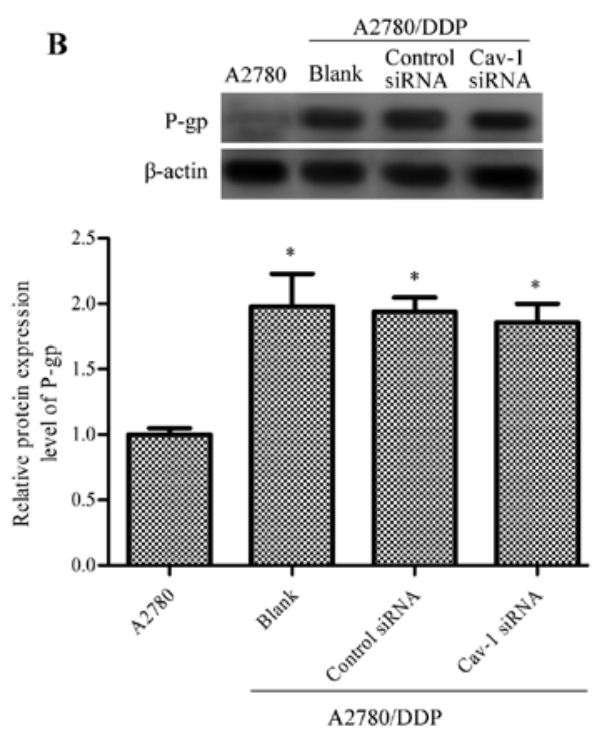

Figure 3. The protein expression level of P-gp in the cisplatin-resistant ovarian cancer cells transfected with Cav-1 siRNA. Western blot images of the protein expression of P-gp after transfecting with Cav-1 siRNA in cisplatin-resistant ovarian cancer cells SKOV3/DDP (A) and A2780/DDP (B) are shown and the column diagram showing the quantification of P-gp. All experiments were repeated at least three times with similar results. Data are shown as mean \pm SEM $(\mathrm{n}=5) .{ }^{*} \mathrm{P}<0.05$ vs. SKOV3 or A2780.

the protein expression level of Notch-1, p-Akt and p-NF-kB p65 using western blot assay in cisplatin-resistant ovarian cancer cells. The results showed that the knockdown of Cav-1 significantly downregulated the protein expression level of Notch-1, p-Akt and p-NF-kB p65 (P<0.05, Fig. 5). These data suggested that the Notch-1/Akt/NF- $\kappa \mathrm{B}$ pathway may be involved in the Cav-1 mediated chemoresistance of ovarian cancer cells.

Overexpression of Cav-1 promotes chemoresistance through Notch-1/Akt/NF-КB in cisplatin-resistant ovarian cancer cells. 
A

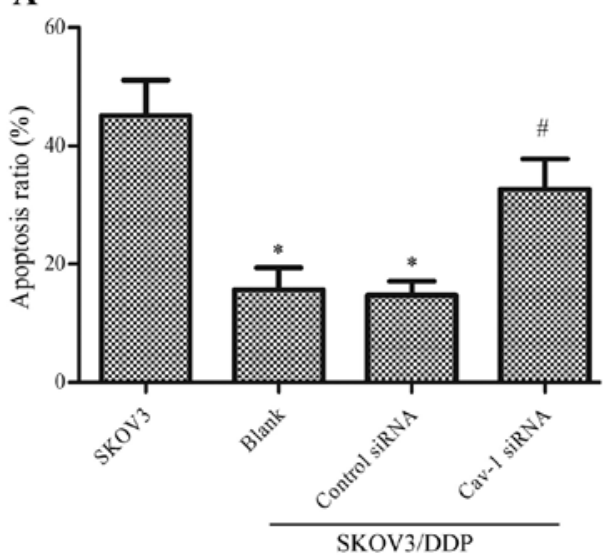

B

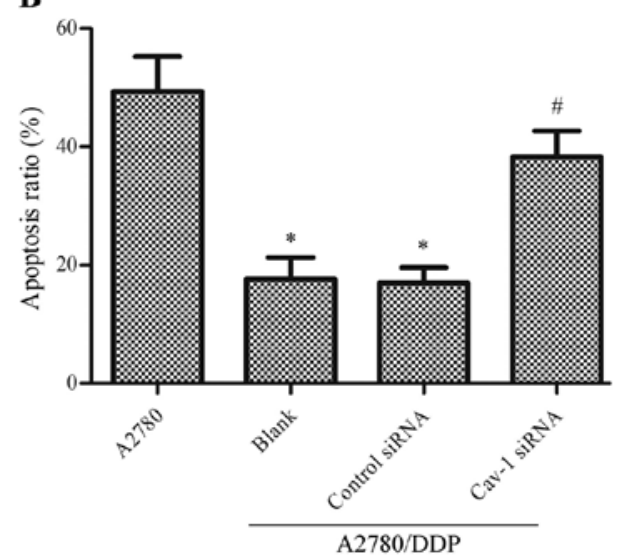

Figure 4. Effect of Cav-1 siRNA on the apoptosis ratio of cisplatin-resistant ovarian cancer cells after exposure to $20 \mu \mathrm{M}$ cisplatin. The apoptosis ratio of (A) SKOV3/DDP and (B) A2780/DPP cells after exposure to $20 \mu \mathrm{M}$ cisplatin was determined by the Annexin V-FITC apoptosis kit. All experiments were repeated at least three times with similar results. Data are shown as mean \pm SEM $(n=5) . ~{ }^{*} \mathrm{P}<0.05$ vs. SKOV3 or A2780, ${ }^{~} \mathrm{P}<0.05$ vs. Blank. Cav-1, caveolin-1.

A

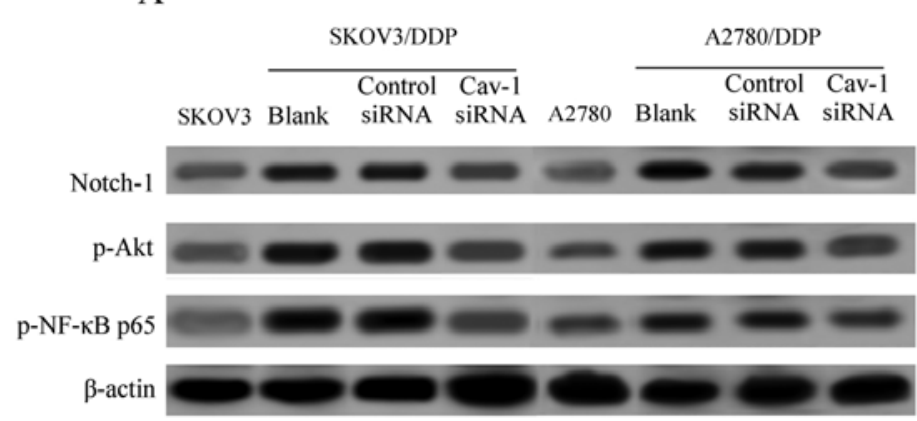

$\mathrm{C}$

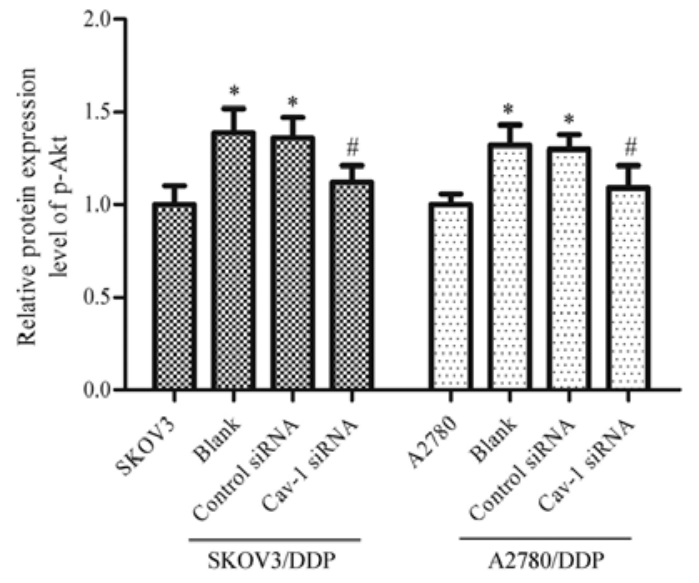

B

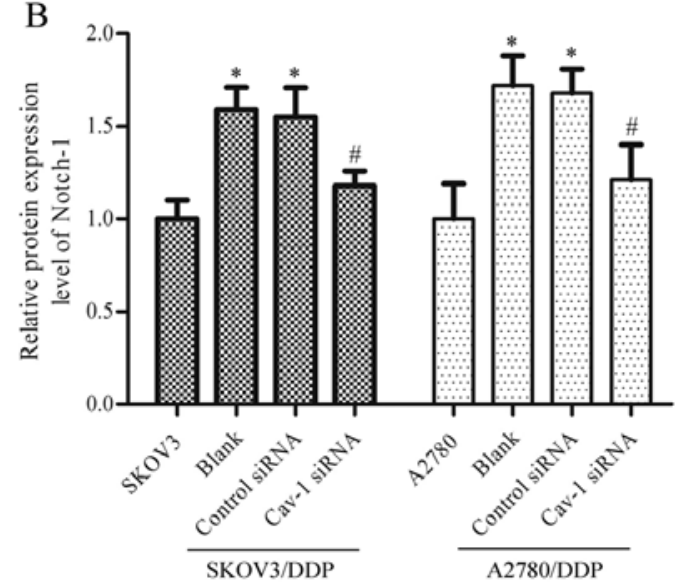

D

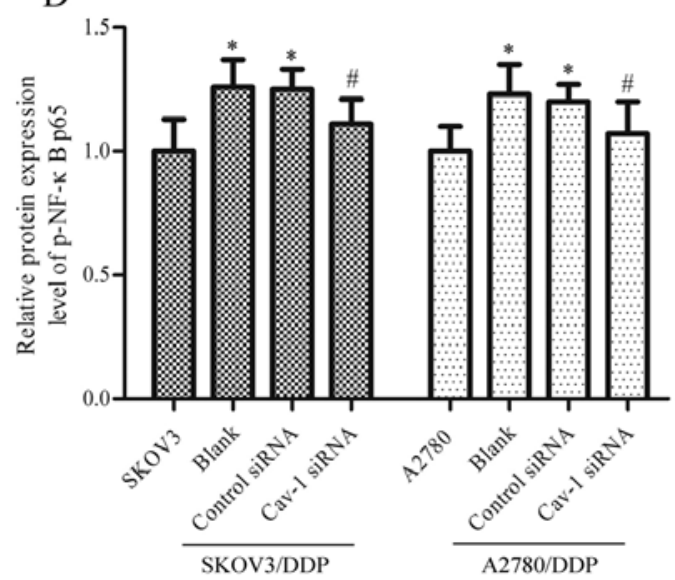

Figure 5. Cav-1 siRNA transfection inhibited the protein expression of Notch-1, p-Akt and p-NF- $\kappa$ B p65 in the cisplatin-resistant ovarian cancer. (A) Respective western blot image of the protein expression of Notch-1, p-Akt and p-NF- $\mathrm{B}$ p65 in normal ovarian cancer cells or cisplatin-resistant ovarian cancer cells transfected with Cav-1 siRNA. The column diagram shows the quantification of Notch-1 (B), p-Akt (C) and p-NF- $\kappa$ B p65 (D). All experiments were repeated at least three times with similar results. Data are shown as mean \pm SEM $(n=5)$. ${ }^{*} \mathrm{P}<0.05$ vs. Blank.

Toconfirm the assumption that Cav-1 regulates chemoresistance of ovarian cancer cells through the Notch-1/Akt/NF- $\mathrm{BB}$ pathway, we overexpressed Cav-1 in cisplatin-resistant ovarian cancer cells by the transfection of the plasmid pcDNA 3.1(+)-cav-1 and inhibited the expression of Notch-1 using Notch-1 siRNA or restrained the activity of Akt and NF- $\mathrm{kB}$ by treating with LY294002 and PDTC, respectively, the $\mathrm{IC}_{50}$ value of cisplatin was assessed using MTT analysis. Overexpression 

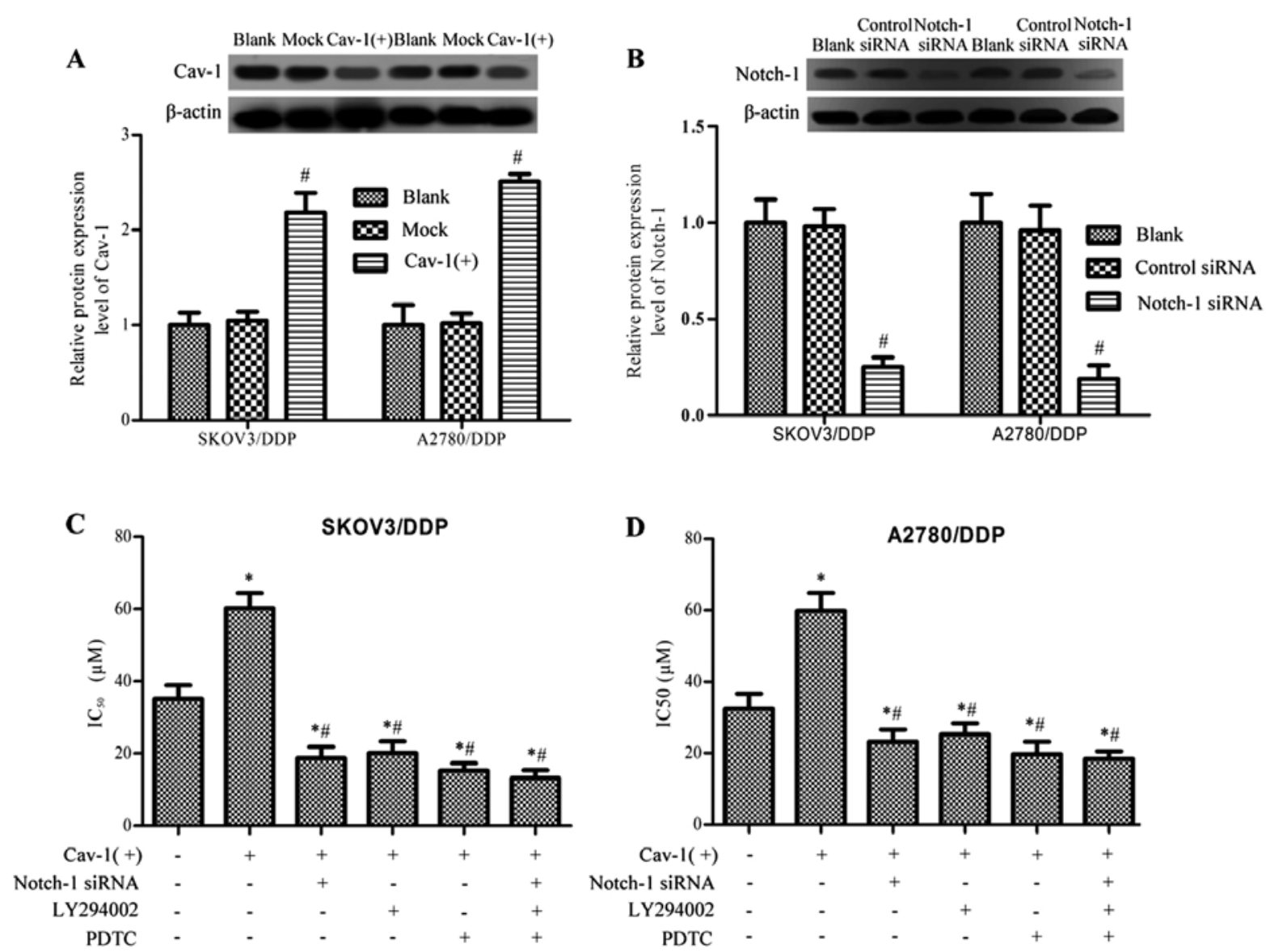

Figure 6. Cav-1 promotes chemoresistance through Notch-1/Akt/NF-кB pathway cisplatin-resistant ovarian cancer. Western blot analysis of Cav-1 expression in plasmid pcDNA 3.1(+)-cav-1 transfected cells (A) and Notch-1 expression in Notch-1 siRNA transfected cells (B). The level of IC ${ }_{50}$ in SKOV3/DDP (C) and A2780/DDP (D) transfected with plasmid pcDNA 3.1(+)-cav-1, Notch-1 siRNA and Akt siRNA, and treated with the inhibitor of NF- $\mathrm{kB}$, PDTC, and was detected by MTT assay. All experiments were repeated at least three times with similar results. Data are shown as mean \pm SEM $(n=5)$. "P<0.05 vs. control, ${ }^{\text {"}} \mathrm{P}<0.05$ vs. Cav- $1(+)$.

of Cav-1 significantly enhanced the $\mathrm{IC}_{50}$ value of cisplatin in both SKOV3/DDP and A2780/DDP cells $(\mathrm{P}<0.05$, Fig. 6C and D). We next detected the effect of downregulated Notch-1, Akt and NF- $\kappa \mathrm{B}$ down on the $\mathrm{IC}_{50}$ value in Cav-1 overexpressed, cisplatin-resistant ovarian cancer cells. The results showed that Notch-1 siRNA, Akt siRNA and the $\mathrm{NF}-\kappa \mathrm{B}$ inhibitor PDTC may all significantly downregulate the $\mathrm{IC}_{50}$ value in Cav-1 overexpressed cisplatin-resistant ovarian cancer cells $(\mathrm{P}<0.05$, Fig. $6 \mathrm{C}$ and $\mathrm{D})$.

\section{Discussion}

In the past 20 years, Cav-1 has become regarded as a tumor suppressor and pro-apoptotic protein (33-35). The reduced expression of Cav-1 is found in several human cancer types, including lung, colon, ovarian, breast cancer and osteosarcomas (18,36-39). However, in recent years, some studies have reported that $\mathrm{Cav}-1$ can exert anti-apoptotic potential, enhance tumor migration and invasion, and have prognostic value for patient survival and cancer recurrence (40-42). In addition, Cav-1 is an essential modulator of cancer MDR. In the present study, we explored the expression level in ovarian cancer cells and cisplatin-resistant ovarian cancer cells using PCR and western blot assay. The results showed that the expression level of Cav-1 in cisplatin-resistant ovarian cancer cells SKOV3/DDP and A2780/DDP is significantly higher than SKOV3 and A2780. In this case, we knocked down Cav-1 in SKOV3/DDP and A2780/DDP by transfecting Cav-1 siRNA and assessed the $\mathrm{IC}_{50}$ value by MTT assay. We found that knockdown of Cav-1 downregulated the $\mathrm{IC}_{50}$ value significantly, both in SKOV3/DDP and A2780/DDP cells. These data suggest for the first time that: i) Cav-1 is upregulated in chemoresistant ovarian cancer; ii) downregulation of Cav-1 may inhibit the cisplatin resistance of ovarian cancer.

Chemoresistance is a major clinical obstacle for the treatment of patients with ovarian cancer and a better understanding of the molecular mechanisms involved in this cellular protection is required to develop more successful therapies. In cisplatin induced drug resistance, expressions of MDR proteins and inhibitions of apoptosis are two important mechanisms that are involved in cisplatin-resistance (43). As the protein product of MDR1 gene, $\mathrm{P}-\mathrm{gp}$ is a membrane protein belonging to the adenosine triphosphate (ATP)binding cassette family. The overexpression of $\mathrm{P}-\mathrm{gp}$ is one of the most common mechanisms that is associated with MDR by inhibiting intracellular drug accumulation and catalyzing the drug efflux (44). Several studies have reported that the expression of P-gp is tightly related to the drug resistance in ovarian cancer cells (45-47). Most of the anticancer therapies, including drugs and chemotherapy, target cancer cells mainly 
by contributing to apoptosis. Indeed, when the cancer cells are chemoresistant, the apoptotic cells induced by anticancer therapy were limited, thus apoptosis resistance is one of the important pathway in mediating the chemoresistance of cancer (29). In the present study, we explored the final effector in Cav-1 mediated cisplatin-resistance. The results showed that the protein expression level of $\mathrm{P}-\mathrm{gp}$ is much higher in cisplatin-resistant than normal cells and there is no connection between the expression of Cav-1 and P-gp. However, knockdown of Cav-1 significantly enhanced the apoptosis ratio induced by cisplatin in cisplatin-resistant ovarian cancer cells, which means that the mediation of chemoresistance by Cav-1 is not targeting P-gp, but cell apoptosis.

The Notch signaling pathway is crucial for the regulation of chemoresistance in cancer by controlling the cell survival and proliferation $(48,49)$. There are four Notch receptors, Notch1, Notch2, Notch3 and Notch4 in mammals, in which Notch1 signaling plays an important role in ovarian tumor growth and is closely associated with chemoresistance in ovarian cancer stem cells $(30,50)$. It is reported that Notch1 may regulate cancer cell growth via activation of the Akt pathway (19), which plays a key regulatory role in cell survival, proliferation, migration and apoptosis. Enhanced Akt kinase activity is involved in resistance to chemotherapeutic agents by regulating the

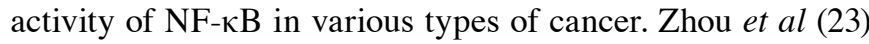
demonstrated that the expression of Notch1 and the activity of Akt1 and NF- $\kappa \mathrm{B}$ were upregulated by doxorubicin (a chemotherapeutic agent), and the Akt1/ NF- $\kappa \mathrm{B} /$ Notch-1 axis has an important role in chemoresistance of gastric cancer cells. Thus, the present study explored the relationship between Notch1, Akt and NF- $\mathrm{KB}$ and the chemoresistance in ovarian cancer cells. We found that the protein level of Notch1, p-Akt and p-NF- $\mathrm{B}$ p65 are all significantly higher in the cisplatin-resistant cancer cells SKOV3/DDP and A2780/DDP than in SKOV3 and A2780 cells, which indicated a role of the Notch1/Akt/NF- $\kappa \mathrm{B}$ pathway in the chemoresistance of ovarian cancer cells.

Recent studies indicated that the Notch1 signaling pathway plays a role in the regulating effect of Cav-1 $(51,52)$. The expression of Cav-1 is associated with the phosphorylation of Akt and the activity of NF- $\mathrm{NB}$. Our results demonstrated that Cav-1 knockdown can significantly down regulate the protein expression level of Notch-1, p-Akt and p-NF- $\mathrm{B}$ p65. To further distinguish the role of the Notch-1/Akt/NF- $\kappa \mathrm{B}$ pathway in the mediation of Cav-1 in chemoresistant ovarian cancer, we inhibited the effect of Notch-1, Akt and NF- $\mathrm{BB}$ in Cav-1 overexpressed, cisplatin-resistant ovarian cancer and detected the $\mathrm{IC}_{50}$ of cisplatin. We found that inhibiting any one of Notch-1, Akt and NF- $\kappa \mathrm{B}$, or all of them, can block the upregulating effect of Cav-1 overexpression on $\mathrm{IC}_{50}$, which suggested a crucial role of NF- $\kappa \mathrm{B} / \mathrm{AKT} /$ Notch-1 pathway in the Cav-1 mediated chemoresistance in ovarian cancer.

In conclusion, our data have shown that Cav-1 is aberrantly expressed and contributes to the chemoresistance in cisplatin-resistant ovarian cancer. We also found that the regulatory effect of Cav-1 on cisplatin-resistance is targeting cell apoptosis rather than $\mathrm{P}-\mathrm{gp}$. Moreover, upregulation of Notch-1, p-Akt, and p-NF- $\mathrm{B}$ p65 was observed in cisplatin-resistant ovarian cancer cells. Furthermore, we demonstrated that knockdown of Cav-1 was able to inhibit the protein expression level of Notch-1, p-Akt and p-NF- $\kappa \mathrm{B}$ p65. Besides, we found that inhibiting the Notch-1/Akt/NF- $\kappa$ B pathway restrained the increased $\mathrm{IC}_{50}$ value induced by Cav-1 overexpression. Overall, the present finding suggests that Cav-1 is a positive factor mediating chemoresistance of ovarian cancer cells by targeting apoptosis through Notch-1/Akt/ $\mathrm{NF}-\kappa \mathrm{B}$ pathway.

\section{Acknowledgements}

The present study was supported by grants from the National Natural Science Foundation of China (no. 81101958 and no. 81101959).

\section{References}

1. Siegel RL, Miller KD and Jemal A: Cancer statistics, 2015. CA Cancer J Clin 65: 5-29, 2015.

2. Kuczynski EA, Sargent DJ, Grothey A and Kerbel RS: Drug rechallenge and treatment beyond progression - implications for drug resistance. Nat Rev Clin Oncol 10: 571-587, 2013.

3. Parton RG and Simons K: The multiple faces of caveolae. Nat Rev Mol Cell Biol 8: 185-194, 2007.

4. Zhang B, Peng F, Wu D, Ingram AJ, Gao B and Krepinsky JC: Caveolin-1 phosphorylation is required for stretch-induced EGFR and Akt activation in mesangial cells. Cell Signal 19: 1690-1700, 2007.

5. Park JH and Han HJ: Caveolin-1 plays important role in EGF-induced migration and proliferation of mouse embryonic stem cells: involvement of PI3K/Akt and ERK. Am J Physiol Cell Physiol 297: C935-C944, 2009.

6. Quest AF, Gutierrez-Pajares JL and Torres VA: Caveolin-1: An ambiguous partner in cell signalling and cancer. J Cell Mol Med 12: 1130-1150, 2008.

7. Chen HL, Fan LF, Gao J, Ouyang JP and Zhang YX: Differential expression and function of the caveolin-1 gene in non-small cell lung carcinoma. Oncol Rep 25: 359-366, 2011.

8. Park J, Bae E, Lee C, Yoon SS, Chae YS, Ahn KS and Won NH: RNA interference-directed caveolin-1 knockdown sensitizes SN12CPM6 cells to doxorubicin-induced apoptosis and reduces lung metastasis. Tumor Biol 31: 643-650, 2010.

9. Rödel F, Capalbo G, Rödel C and Weiss C: Caveolin-1 as a prognostic marker for local control after preoperative chemoradiation therapy in rectal cancer. Int J Radiat Oncol Biol Phys 73: 846-852, 2009

10. Hehlgans S, Eke I, Storch K, Haase M, Baretton GB and Cordes N: Caveolin-1 mediated radioresistance of 3D grown pancreatic cancer cells. Radiother Oncol 92: 362-370, 2009.

11. Burrows AD, Restall C, Sloan EK and Anderson RL: The contribution of stromal caveolin-1 to breast cancer metastasis. Cancer Res 72: 1486-1486, 2012.

12. Rao X, Evans J, Chae H, Pilrose J, Kim S, Yan P, Huang RL, Lai HC, Lin H, Liu Y, et al: CpG island shore methylation regulates caveolin-1 expression in breast cancer. Oncogene 32: 4519-4528, 2013

13. Xu J, Agyemang S, Qin Y, Aysola K, Giles M, Oprea G, O'Regan RM, Partridge EE, Harris-Hooker S, Rice VM, et al: A novel pathway that links Caveolin-1 down-regulation to BRCA1 dysfunction in serous epithelial ovarian cancer cells. Enliven Chall Cancer Detect Ther 1: pii004, 2014.

14. Goetz JG, Lajoie P, Wiseman SM and Nabi IR: Caveolin-1 in tumor progression: The good, the bad and the ugly. Cancer Metastasis Rev 27: 715-735, 2008.

15. Cai $\mathrm{C}$ and Chen J: Overexpression of caveolin-1 induces alteration of multidrug resistance in Hs578T breast adenocarcinoma cells. Int J Cancer 111: 522-529, 2004.

16. Selga E, Morales C, Noe V, Peinado MA and Ciudad CJ: Role of caveolin 1, E-cadherin, Enolase 2 and PKCalpha on resistance to methotrexate in human HT29 colon cancer cells. BMC Med Genomics 1: 1755-8794, 2008.

17. Ho CC, Kuo SH, Huang PH, Huang HY, Yang CH and Yang PC: Caveolin-1 expression is significantly associated with drug resistance and poor prognosis in advanced non-small cell lung cancer patients treated with gemcitabine-based chemotherapy. Lung Cancer 59: 105-110, 2008. 
18. Wiechen K, Diatchenko L, Agoulnik A, Scharff KM, Schober H, Arlt K, Zhumabayeva B, Siebert PD, Dietel M, Schäfer R, et al: Caveolin-1 is down-regulated in human ovarian carcinoma and acts as a candidate tumor suppressor gene. Am J Pathol 159: 1635-1643, 2001.

19. Liu ZJ, Xiao M, Balint K, Smalley KS, Brafford P, Qiu R, Pinnix CC, Li X and Herlyn M: Notchl signaling promotes primary melanoma progression by activating mitogen-activated protein kinase/phosphatidylinositol 3-kinase-Akt pathways and up-regulating N-cadherin expression. Cancer Res 66: 4182-4190, 2006.

20. Aoki K, Ogawa T, Ito Y and Nakashima S: Cisplatin activates survival signals in UM-SCC-23 squamous cell carcinoma and these signal pathways are amplified in cisplatin-resistant squamous cell carcinoma. Oncol Rep 11: 375-379, 2004.

21. Wang Z, Li Y, Banerjee S, Kong D, Ahmad A, Nogueira V, Hay N and Sarkar FH: Down-regulation of Notch-1 and Jagged-1 inhibits prostate cancer cell growth, migration and invasion, and induces apoptosis via inactivation of Akt, mTOR, and NF-kappaB signaling pathways. J Cell Biochem 109: 726-736, 2010.

22. Romashkova JA and Makarov SS: NF- $\kappa$ B is a target of AKT in anti-apoptotic PDGF signalling. Nature 401: 86-90, 1999.

23. Zhou W, Fu XQ, Zhang LL, Zhang J, Huang X, Lu XH, Shen L, Liu BN,Liu J,LuoHS, etal:The AKT1/NF-kappaB/Notch1/PTEN axis has an important role in chemoresistance of gastric cancer cells. Cell Death Dis 4: e847, 2013.

24. Zhu H, Bhaijee F, Ishaq N, Pepper DJ, Backus K, Brown AS, Zhou X and Miele L: Correlation of Notch1, pAKT and nuclear $\mathrm{NF}-\mathrm{\kappa B}$ expression in triple negative breast cancer. Am J Cancer Res 3: 230, 2013.

25. Wang S, Kan Q, Sun Y, Han R, Zhang G, Peng T and Jia Y: Caveolin-1 regulates neural differentiation of rat bone mesenchymal stem cells into neurons by modulating Notch signaling. Int J Dev Neurosci 31: 30-35, 2013.

26. Chanvorachote $\mathrm{P}$, Chunhacha $\mathrm{P}$ and Pongrakhananon V: Caveolin-1 induces lamellipodia formation via an Akt-dependent pathway. Cancer Cell Int 14: 1475-2867, 2014.

27. Hada N, Okayasu M, Ito J, Nakayachi M, Hayashida C, Kaneda T, Uchida N, Muramatsu T, Koike C, Masuhara M, et al: Receptor activator of NF- $\kappa \mathrm{B}$ ligand-dependent expression of caveolin-1 in osteoclast precursors, and high dependency of osteoclastogenesis on exogenous lipoprotein. Bone 50: 226-236, 2012.

28. Schmittgen TD and Livak KJ: Analyzing real-time PCR data by the comparative C(T) method. Nat Protoc 3: 1101-1108, 2008.

29. Rebucci $M$ and Michiels C: Molecular aspects of cancer cell resistance to chemotherapy. Biochem Pharmacol 85: 1219-1226, 2013.

30. Groeneweg JW, Foster R, Growdon WB, Verheijen RH and Rueda BR: Notch signaling in serous ovarian cancer. J Ovarian Res 7: 95, 2014.

31. Liu L-Z, Zhou X-D, Qian G, Shi X, Fang J and Jiang B-H: AKT1 amplification regulates cisplatin resistance in human lung cancer cells through the mammalian target of rapamycin/p70S6K1 pathway. Cancer Res 67: 6325-6332, 2007.

32. Zhong H, Voll RE and Ghosh S: Phosphorylation of NF- $\kappa B$ p65 by PKA stimulates transcriptional activity by promoting a novel bivalent interaction with the coactivator CBP/p300. Mol Cell 1: 661-671, 1998

33. Bélanger MM, Roussel E and Couet J: Caveolin-1 is down-regulated in human lung carcinoma and acts as a candidate tumor suppressor gene. Chest 125 (5 Suppl): 106S, 2004.

34. Razani B, Schlegel A, Liu J and Lisanti M: Caveolin-1, a putative tumour suppressor gene. Biochem Soc Trans 29: 494-499, 2001.
35. Huertas-Martínez J, Barrau I, Sainz-Jaspeado M, Lagares-Tena L, Mateo-Lozano S, Mora J, Roma J, Gallego S, Moran S, Esteller M, et al: Caveolin-1 acts as a tumor suppressor promoting muscular differentiation in alveolar rhabdomyosarcomas. Cancer Res 73: $3827,2013$.

36. Wikman H, Kettunen E, Seppänen JK, Karjalainen A, Hollmén J, Anttila $S$ and Knuutila S: Identification of differentially expressed genes in pulmonary adenocarcinoma by using cDNA array. Oncogene 21: 5804-5813, 2002.

37. Lee SW, Reimer CL, Oh P, Campbell DB and Schnitzer JE: Tumor cell growth inhibition by caveolin re-expression in human breast cancer cells. Oncogene 16: 1391-1397, 1998.

38. Bender FC, Reymond MA, Bron C and Quest AF: Caveolin-1 levels are down-regulated in human colon tumors, and ectopic expression of caveolin-1 in colon carcinoma cell lines reduces cell tumorigenicity. Cancer Res 60: 5870-5878, 2000.

39. Cantiani L, Manara MC, Zucchini C, De Sanctis P, Zuntini M, Valvassori L, Serra M, Olivero M, Di Renzo MF, Colombo MP, et al: Caveolin-1 reduces osteosarcoma metastases by inhibiting c-Src activity and met signaling. Cancer Res 67: 7675-7685, 2007.

40. Tang Y, Zeng X, He F, Liao Y, Qian N and Toi M: Caveolin-1 is related to invasion, survival, and poor prognosis in hepatocellular cancer. Med Oncol 29: 977-984, 2012.

41. Wang R, He W, Li Z, Chang W, Xin Y and Huang T: Caveolin-1 functions as a key regulator of $17 \beta$-estradiol-mediated autophagy and apoptosis in BT474 breast cancer cells. Int J Mol Med 34: 822-827, 2014.

42. Karam JA, Lotan Y, Roehrborn CG, Ashfaq R, Karakiewicz PI and Shariat SF: Caveolin-1 overexpression is associated with aggressive prostate cancer recurrence. Prostate 67: 614-622, 2007.

43. Florea A-M and Büsselberg D: Cisplatin as an anti-tumor drug: Cellular mechanisms of activity, drug resistance and induced side effects. Cancers (Basel) 3: 1351-1371, 2011.

44. Cole SP, Bhardwaj G, Gerlach JH, Mackie JE, Grant CE, Almquist KC, Stewart AJ, Kurz EU, Duncan AM and Deeley RG: Overexpression of a transporter gene in a multidrug-resistant human lung cancer cell line. Science 258: 1650-1654, 1992.

45. Stordal B, Hamon M, McEneaney V, Roche S, Gillet JP, O'Leary JJ, Gottesman M and Clynes M: Resistance to paclitaxel in a cisplatin-resistant ovarian cancer cell line is mediated by P-glycoprotein. PLoS One 7: e40717, 2012.

46. Bourhis J, Goldstein LJ, Riou G, Pastan I, Gottesman MM and Bénard J: Expression of a human multidrug resistance gene in ovarian carcinomas. Cancer Res 49: 5062-5065, 1989.

47. van der Zee AG, Hollema H, Suurmeijer AJ, Krans M, Sluiter WJ, Willemse PH, Aalders JG and de Vries EG: Value of P-glycoprotein, glutathione S-transferase pi, c-erbB-2, and p53 as prognostic factors in ovarian carcinomas. J Clin Oncol 13: 70-78, 1995.

48. Bray SJ: Notch signalling: a simple pathway becomes complex. Nat Rev Mol Cell Biol 7: 678-689, 2006.

49. Perdigoto $\mathrm{CN}$ and Bardin AJ: Sending the right signal: Notch and stem cells. Biochim Biophys Acta 1830: 2307-2322, 2013.

50. Hopfer O, Zwahlen D, Fey M and Aebi S: The Notch pathway in ovarian carcinomas and adenomas. Br J Cancer 93: 709-718, 2005.

51. Yanjie J, Jiping S, Yan Z, Xiaofeng Z, Boai Z and Yajun L: Effects of Notch-1 signalling pathway on differentiation of marrow mesenchymal stem cells into neurons in vitro. Neuroreport 18 : 1443-1447, 2007.

52. Campos LS, Decker L, Taylor V and Skarnes W: Notch, epidermal growth factor receptor, and betal-integrin pathways are coordinated in neural stem cells. J Biol Chem 281: 5300-5309, 2006. 